\title{
Percepções de futuros educadores/professores face à Inclusão de alunos com necessidades educativas especiais: Um estudo comparativo entre Portugal e Tailândia
}

\author{
Ana Paula Loução Martins ${ }^{a}$, Paula Marisa Fortunato Vaz ${ }^{b}$, Sasinan \\ Sirithadakunlaphat ${ }^{\mathrm{c}}$ \\ ${ }^{a}$ Centro de Investigação em Educação, Instituto de Educação, Universidade do Minho, Braga, \\ Portugal, apmartins@ie.uminho.pt, ${ }^{\mathrm{b} I n s t i t u t o ~ P o l i t e ́ c n i c o ~ d e ~ B r a g a n c ̧ a, ~ E s c o l a ~ S u p e r i o r ~ d e ~ E d u c a c ̧ a ̃ o, ~}$ \\ Bragança, Portugal, paulavaz@ipb.pt, ${ }^{c}$ Faculty of Education, Burapha University, ChonBuri \\ Thailand,ssasinan@gmail.com
}

\begin{abstract}
Resumo
Na presente comunicação apresentam-se resultados dum estudo que teve por objetivo conhecer e comparar as percepções de futuros educadores $e$ professores portugueses e tailandeses acerca da inclusão de alunos com NEE. Recolheram-se dados através dum questionário junto duma amostra de 333 futuros educadores/professores de duas instituições de ensino superior, uma Portuguesa (112) e uma Tailandesa (221). A análise dos resultados permite concluir que que: a) Os futuros educadores/professores portugueses têm uma atitude mais positiva em relação à educação dos alunos com NEE em turmas regulares e que em muitos dos itens essa diferença é estatisticamente significativa; b) a severidade da NEE parece ter influência na atitude dos participantes de ambos os países, sendo que concordam mais com a ideia de beneficios da inclusão para os alunos com NEE ligeiras do que severas; c) existe uma atitude muito positiva em relação à ideia de que as pessoas com necessidades especiais têm o direito de serem incluídas na comunidade, com mais de 90\% dos participantes de ambos os paises a concordarem e concordarem plenamente com a mesma. Por fim, são discutidas as implicações destes resultados para a formação de professores e para a qualidade da educação dos alunos com NEE numa perspetiva internacional.
\end{abstract}

Palavras-chave: inclusão, percepções, futuros professores, necessidades educativas especiais. 
Atitudes de futuros educadores/professores face à Inclusão de alunos com Necessidades Educativas Especiais: Um estudo comparativo entre Portugal e Tailândia

\section{Introdução}

A escola deve integrar as novas competências culturais e tecnológicas da sociedade, e deve apresentar-se como um local diversificado, que responde "às necessidades, e apoia as diferenças e a aprendizagem de todas as crianças, independentemente das suas condições físicas, sociais, linguísticas ou outras" (UNESCO, 1994). Está aqui incluída uma diversidade de alunos, entre os quais, alunos com necessidades educativas especiais (NEE), que podem, durante todo ou parte do seu percurso escolar, necessitar de um atendimento prestado pelos serviços de educação especial. A inclusão das crianças/jovens com NEE na sociedade iniciou-se nos anos 60 e continua a ser largamente debatida nos dias de hoje. Os profissionais que, ao longo dos tempos, se têm empenhado na implementação da inclusão podem orgulhar-se de ter conseguido reduzir o número de alunos com NEE que frequentam escolas de educação especial. Muitos deles, contudo, só ficarão satisfeitos quando as escolas de educação especial e as salas de apoio forem totalmente eliminadas, e todos os alunos com NEE forem educados em classes regulares, a tempo inteiro. Actualmente, mesmo os defensores menos radicais da inclusão, recomendam um grau de interacção entre alunos com NEE e estudantes sem este género de problemas, nunca imaginado pelos professores de educação especial que desempenharam funções docentes nos anos 60 e 70 (Hallahan \& Kauffman, 1997).

Globalmente, a filosofia e a prática da inclusão de alunos com necessidades educativas especiais em salas de aula regulares têm vindo a ser implementadas e, embora em diferentes estádios, estão na agenda educativa em muitos países. Na Tailândia a legislação nacional que garante a defesa dos alunos com NEE a uma educação básica pública grátis foi aprovada em 1999 (Office of Special Education Administration, 2014) e em 2008 numa lei específica para as necessidades educativas especiais, que indica os seguintes direitos destes alunos: a) a partir do nascimento ou do momento do diagnóstico e ao longo da vida, têm direito a uma educação gratuita e a receber materiais tecnológicos e educativos; 2) devem ter oportunidade de frequentar uma escola de acordo com as suas características, interesses, pontos fortes e necessidades; 3) devem receber uma educação com um alto nível de qualidade, em instituições acreditadas, incluindo um desenho curricular apropriado e uma avaliação das suas necessidades especiais (Office of Special Education Administration, 2015). Este país está ainda a dar os seus primeiros passos na implementação de uma educação inclusiva e, portanto, está ainda a transitar da ideia para a implementação (Vorapanyaa \& Dunlap, 2014). Em Portugal, a inclusão começou nos anos 70 e atualmente é legislada pelo Decreto-lei 3/2008 de 7 de janeiro, que define os apoios especializados que devem ser prestados na educação pré-escolar e nos ensinos básico e secundário tanto nas escolas públicas, como nas particulares, de modo a criar condições para a adequação do processo educativo às NEE dos alunos. Assim, as crianças e os jovens com NEE de caráter permanente têm direito, tal como as restantes crianças, a frequentar o jardim de infância ou 
a escola, a ver reconhecidas as suas especificidades e a receber respostas educativas adequadas às mesmas (Decreto-lei 3/2008 de 7 de janeiro).

De acordo com os pressupostos da filosofia inclusiva, os alunos com NEE são, sempre que possível, educados na classe regular, pelo professor titular da turma, num processo de colaboração com o professor de educação especial, ou com outros profissionais (e com os pais). Os professores, quer sejam professores titulares de turma, quer sejam professores de educação especial, desempenham um papel crucial na aplicação dos princípios da filosofia inclusiva. Considerando que as percepções dos professores afectam o seu comportamento perante determinados grupos de alunos, vários investigadores têm desenvolvido estudos no domínio das atitudes dos professores. Geralmente, têm mostrado que existe uma relação directa entre a percepção dos professores e o seu comportamento (Smith, Polloway, Patton, \& Dowdy, 1995).

Neste contexto, este estudo foi, assim, desenvolvido com o objetivo de conhecer e comparar as percepções de futuros educadores e professores portugueses e tailandeses acerca da inclusão de alunos com NEE na classe regular.

\section{Método}

\subsection{Participantes}

Neste estudo participaram 333 futuros educadores/professores de duas instituições de ensino superior, uma Portuguesa e uma Tailandesa. Destes, 112 são alunos portugueses (92 raparigas e 20 rapazes) e 221 são alunos tailandeses (154 raparigas e 66 rapazes) ${ }^{1}$.

Dos 112 alunos portugueses, 79 são alunos da licenciatura em Educação Básica e 33 frequentam diferentes mestrados profissionalizantes para a docência. Dos 221 alunos tailandeses, todos os respondentes são alunos de bacharelato (nível correspondente à licenciatura em Educação Básica que em Portugal tem a duração de três anos).

Os participantes foram caraterizados relativamente ao facto de já terem participado ou não num curso de formação em Educação Especial, tendo-se verificado que a maioria, tanto dos alunos portugueses $(95,5 \%)$, como dos alunos tailandeses nunca participou $(83,6 \%)$.

Os participantes foram caraterizados também relativamente ao facto de já terem conhecido, conhecerem ou terem contactado com crianças com NEE ou adultos com NE, situação que se verificou na maioria dos casos tanto nos alunos portugueses $(83,9)$ como nos alunos tailandeses $(96,4)$.

Relativamente à possibilidade de no futuro virem a ensinar crianças com NEE, a maioria

\footnotetext{
${ }^{1}$ Houve um valor omisso.
} 
Atitudes de futuros educadores/professores face à Inclusão de alunos com Necessidades Educativas Especiais: Um estudo comparativo entre Portugal e Tailândia

dos participantes portugueses e tailandeses refere ser moderadamente possível, como se pode verificar na Tabela 1 .

Tabela 1: Possibilidade de no futuro ensinar crianças com NEE

\begin{tabular}{|c|c|c|}
\hline & Portugueses & Tailandeses \\
\hline Possibilidade & $\mathrm{n}(\%)$ & $\mathrm{n} *(\%)$ \\
\hline Extremamente possível & $41(36,6)$ & $12(5,5)$ \\
\hline Moderadamente possível & $\mathbf{5 9 ( 5 2 , 7 )}$ & $\mathbf{1 0 9}(\mathbf{4 9 , 5 )}$ \\
\hline Pouco possível & $9(8,0)$ & $76(34,5)$ \\
\hline Não é possível & $3(2,7)$ & $23(10,5)$ \\
\hline
\end{tabular}

\subsection{Procedimentos de recolha e de dados}

Para a recolha de dados, neste estudo, que tem caráter quantitativo, usou-se como instrumento de recolha de dados um questionário intitulado "Perceções de futuros professores relativamente à inclusão de alunos com necessidades educativas especiais" elaborado por duas investigadoras do Centro de Investigação em Educação da Universidade do Minho, Martins e Santos (2012) no âmbito de dois estudos de mestrado (ver por exemplo, Khamsouvannong, 2012). Este instrumento foi traduzido pela terceira autora para ser usado na recolha de dados junto dos alunos tailandeses. Na Tailândia os dados foram recolhidos pela primeira e terceira autoras durante as últimas duas semanas do mês de Maio e primeira de junho de 2015. Em Portugal, os dados foram recolhidos pela segunda autora em junho de 2016. Em ambos os países foi previamente solicitada autorização às instituições de ensino superior em causa e, posteriormente, foi acordada a forma de recolha de dados. No geral, o preenchimento fez-se ou no início de uma aula, ou no final, conforme opção do docente em questão, na presença do mesmo e de uma das investigadoras deste estudo.

O questionário é formado por duas partes, a primeira parte relacionada com dados sociodemográficos e a segunda parte relativa às percepções acerca da inclusão, constituída por 21 questões a serem preenchidas numa escala de Likert, com quatro respostas possíveis "Discordo Totalmente", "Discordo", “Concordo", "Concordo Plenamente”.. 


\section{Resultados}

Utilizamos estatística descritiva, nomeadamente percentagens e inferencial (testes paramétricos, teste $t$ para $p \leq 0,05)$ para tratamento de dados e delineamento de resultados que apresentamos de seguida:

1. Relativamente ao ambiente de aprendizagem (ver Tabela 2) a maioria dos participantes portugueses (PT) e tailandeses (TH) concorda e concorda plenamente que os alunos com NEE devem ser educados em turmas regulares. A maioria dos alunos portugueses discorda e discorda totalmente da colocação dos alunos com NEE em turmas separadas. No caso dos alunos tailandeses aproximadamente metade, concorda e concorda plenamente com a colocação dos alunos com NEE em turmas separadas. Relativamente à colocação de alunos com NEE em escolas especiais a maioria dos alunos portugueses discorda e discorda totalmente desta situação e a maioria dos alunos tailandeses concorda e concorda plenamente com a mesma.

Tabela 2: Distribuição dos resultados para os itens relativos aos ambientes de aprendizagem

\begin{tabular}{|c|c|c|c|c|c|c|}
\hline \multirow{3}{*}{ Itens/país } & \multicolumn{2}{|c|}{ Turmas regulares } & \multicolumn{2}{|c|}{ Turmas separadas } & \multicolumn{2}{|c|}{ Escolas Especiais } \\
\hline & PT & TH & PT & TH & PT & TH \\
\hline & n (\%) & n (\%) & n (\%) & n (\%) & $n *(\%)$ & n (\%) \\
\hline $\begin{array}{l}\text { Discordo } \\
\text { totalmente }\end{array}$ & $4(3,6)$ & $4(1,8)$ & $47(42,0)$ & $5(2,3)$ & $27(24,3)$ & $1(0,5)$ \\
\hline Discordo & $18(16,1)$ & $82(37,1)$ & $47(42,0)$ & $102(46,2)$ & $52(46,8)$ & $32(14,5)$ \\
\hline Concordo & $60(53,6)$ & $124(56,1)$ & $17(15,2)$ & $100(45,2)$ & $23(20,7)$ & $153(69,2)$ \\
\hline $\begin{array}{l}\text { Concordo } \\
\text { plenamente }\end{array}$ & $30(26,8)$ & $11(5,0)$ & $1(0,9)$ & $14(6,3)$ & $9(8,1)$ & $35(15,8)$ \\
\hline
\end{tabular}

$*_{\mathrm{n}}=111$, dado que houve um valor omisso.

2. No que respeita aos benefícios da inclusão, a maioria dos participantes portugueses concorda e concorda plenamente com o facto de a inclusão dos alunos com NEE em turmas regulares poder ser benéfica para as suas famílias $(86,6 \%)$, para a comunidade $(86,6 \%)$, para os alunos com NEE $(85,7 \%)$, para os alunos sem NEE $(80,2 \%)$ e também para os professores das turmas $(68,8)$. Também a maioria dos participantes tailandeses concorda e concorda plenamente com o benefícioda inclusão para os mesmos intervenientes referidos, mas pela seguinte ordem: alunos com NEE (90\%), famílias dos alunos com NEE $(87,8)$, 
Atitudes de futuros educadores/professores face à Inclusão de alunos com Necessidades Educativas Especiais: Um estudo comparativo entre Portugal e Tailândia

comunidade $(81 \%)$, professors $(71,1 \%)$, alunos sem NEE $(67,8 \%)$.

3. Quanto aos benefícios da inclusão em função da severidade da NEE (ver Tabela 3), verificou-se que relativamente às NEE ligeiras e moderadas a maioria dos participantes, portugueses (95,5\% e 90,1\% respetivamente) e tailandeses (90,5\% e 96\% respetivamente), concorda e concorda plenamente com o facto de a inclusão em turmas regulares poder beneficiar estes alunos. Já relativamente às NEE severas, a maioria dos participantes discorda e discorda totalmente com o benefício da inclusão em turmas regulares para estes alunos. Apenas 42,9\% dos portugueses e 30,3\% dos tailandeses concorda e concorda plenamente com a existência de benefícios para os alunos com NEE severas. Percebe-se então que a atitude dos participantes acerca dos benefícios da inclusão é influenciada pela severidade da NEE.

Tabela 3: Distribuição dos resultados para os itens relativos aos benefícios da inclusão em função da severidade da NEE

\begin{tabular}{|c|c|c|c|c|c|c|}
\hline \multirow{3}{*}{ Itens/país } & \multicolumn{2}{|c|}{ NEE ligeiras } & \multicolumn{2}{|c|}{ NEE moderadas } & \multicolumn{2}{|c|}{ NEE severas } \\
\hline & PT & TH & PT & TH & PT & TH \\
\hline & n (\%) & n (\%) & $n *(\%)$ & n (\%) & $n *(\%)$ & n (\%) \\
\hline $\begin{array}{c}\text { Discordo } \\
\text { Totalmente }\end{array}$ & $0(0)$ & $0(0)$ & $2(1,8)$ & $0(0)$ & $24(21,4)$ & $46(\mathbf{2 0 , 8})$ \\
\hline Discordo & $5(4,5)$ & $21(9,5)$ & $9(8,1)$ & $9(4,1)$ & $40(35,7)$ & $108(\mathbf{4 8 , 9})$ \\
\hline Concordo & $69(61,6)$ & $176(79,6)$ & $70(63,1)$ & $163(73,8)$ & $43(38,4)$ & $60(27,1)$ \\
\hline $\begin{array}{l}\text { Concordo } \\
\text { Plenamente }\end{array}$ & $38(\mathbf{3 3}, \mathbf{9})$ & $24(\mathbf{1 0 , 9 )}$ & $30(\mathbf{2 7 , 0})$ & $49(\mathbf{2 2}, \mathbf{2})$ & $5(4,5)$ & $7(3,2)$ \\
\hline
\end{tabular}

$*_{n}=111$, dado que houve um valor omisso.

4. No que respeita à atitude relativa aos benefícios da inclusão para alunos com diferentes NEE, verifica-se que os participantes portugueses maioritariamente concordam e concordam plenamente com os benefícios da inclusão em turmas regulares, de alunos com qualquer das NEE indicadas. No entanto este número de participantes é maior quando se trata de NEE como a dislexia $(81,3 \%)$, as dificuldades intelectuais $(78,6 \%)$ e os problemas motores $(77,5 \%)$ do que quando se trata de problemas de comportamento $(73,2 \%)$, de problemas visuais $(64,3 \%)$ e de problemas auditivos $(55,8 \%)$. No caso dos participantes 
tailandeses, estes concordam e concordam plenamente com os benefícios da inclusão em turmas regulares, de alunos com problemas motores (66,5\%), problemas de comportamento $(63,8 \%)$ e dislexia $(57,9 \%)$. A maioria discorda e discorda totalmente dos benefícios da inclusão em turmas regulares para alunos com problemas auditivos (62\%), dificuldades intelectuais $(61,5 \%)$ e problemas visuais $(54,3 \%)$.

5. Quanto ao impacto positivo da inclusão em turmas regulares, como se pode verificar na Tabela 4, a maioria dos participantes portugueses e tailandeses concorda e concorda plenamente que este existe efetivamente, sendo contudo mais elevado o número de participantes que concorda e concorda plenamente com o impacto positivo da inclusão no progresso social do que no progresso académico.

Tabela 4: Distribuição dos resultados para os itens relativos ao impacto da inclusão no progresso dos alunos com NEE

\begin{tabular}{|c|c|c|c|c|}
\hline \multirow{2}{*}{ Itens/país } & \multicolumn{2}{|c|}{ Impacto académico } & \multicolumn{2}{c|}{ Impacto social } \\
\cline { 2 - 5 } & PT & TH & PT & TH \\
\cline { 2 - 5 } & $\mathbf{n ~ ( \% )}$ & $\mathbf{n ~ ( \% )}$ & $\mathbf{n} *(\%)$ & $\mathbf{n}(\%)$ \\
\hline Discordo Totalmente & $5(4,5)$ & $4(1,8)$ & $3(2,7)$ & $2(0,9)$ \\
\hline Discordo & $12(10,7)$ & $60(27,3)$ & $7(6,3)$ & $41(18,6)$ \\
\hline Concordo & $\mathbf{6 7 ( 5 9 , 8 )}$ & $\mathbf{1 3 9 ( 6 3 , 2 )}$ & $\mathbf{6 4}(\mathbf{5 7 , 1 )}$ & $\mathbf{1 5 3 ( 6 9 , 5 )}$ \\
\hline Concordo Plenamente & $\mathbf{2 8 ( 2 5 , 0 )}$ & $\mathbf{1 7 ( 7 , 7 )}$ & $\mathbf{3 8 ( 3 3 , 9 )}$ & $\mathbf{2 4}(\mathbf{1 0 , 9 )}$ \\
\hline
\end{tabular}

* $\mathrm{n}=220$ dado que houve um valor omisso

6. A a maioria dos participantes portugueses $(64,3 \%)$ e tailandeses $(58,4 \%)$ concorda e concorda plenamente com o facto de a colocação de alunos com NEE nas turmas regulares ser disruptiva para os alunos sem NEE.

7. A quase totalidade dos participantes portugueses $(97,3 \%)$ e tailandeses $(97,7 \%)$ concorda e concorda plenamente com o direito de as pessoas com NEE serem incluídas na sociedade.

8. A análise inferencial dos dados indica que a variável nacionalidade teve significado estatístico em 12 dos 21 itens do questionário, sendo que em todos os itens a média dos participantes portugueses mostra uma atitude mais positiva em relação aos tailandeses.

9. Calculou-se o Alfa de Cronbach's para os 31 itens, tendo-se obtido um valor de 0,879 para os resultados dos participantes portugueses e de 0,812 dos tailandeses. Ambos os 
Atitudes de futuros educadores/professores face à Inclusão de alunos com Necessidades Educativas Especiais: Um estudo comparativo entre Portugal e Tailândia

valores dão-nos indicação de que os itens que constituem o questionário têm boa consistência interna com esta amostra (Pestana \& Gageiro, 2008).

\section{Conclusões e discussão}

A inclusão é uma filosofia que, transcendendo o espaço físico da escola, se relaciona com questões éticas e morais. Segundo Lieberman (1996):

os pontos a favor da inclusão são muito poderosos, em termos emocionais. Não são fáceis de pôr em questão e nem sempre podem ser tratados de forma racional. Os argumentos usados reflectem ideias extensíveis a toda a humanidade. São apresentadas imagens que apontam para a amizade, a lealdade, o sentido de grupo, a unidade, a dedicação, a solicitude e atenção verdadeiras, a construção de uma sociedade que se oriente pela reciprocidade de interesses. (p.16)

Tendo por pilar estes valores, a filosofia da inclusão deve ser analisada por todos os cidadãos, e não apenas pelos investigadores. Para Lieberman (1996), o objectivo não consiste em questionar as ideias, mas a estratégia seguida para a implementação do modelo inclusivo. Neste estudo analisamos as perspetivas de futuros educadores/professores que estudam em países com realidades diferentes no que respeita à inclusão de alunos com NEE. Concluímos que:

a) Os futuros educadores/professores portugueses têm uma atitude mais positiva em relação à educação dos alunos com NEE em turmas regulares e que em muitos dos itens esse diferença é estatisticamente significativa;

b) a severidade da NEE parece ter influência na atitude dos participantes de ambos os países, sendo que concordam mais com a ideia de benefícios da inclusão para os alunos com NEE ligeiras do que severas;

c) existe uma atitude muito positiva em relação à ideia de que as pessoas com necessidades especiais têm o direito de serem incluídas na comunidade, com mais de $90 \%$ dos participantes de ambos os países a concordarem e concordarem plenamente com a mesma.

Enquanto não parece haver um consenso entre todos acerca do conceito e da implementação da filosofia da inclusão sublinhamos as palavras de Heumann (1994), citado por Coutinho e Repp (1999, pp 15-16):

Quando tomamos decisões sobre a educação dos alunos com NEE, não advogamos um 'tamanho único para todos'. Decisões sobre o melhor ambiente educativo devem ser tomadas a nível local, com base nas necessidades individuais dos alunos. Qualquer outra abordagem não deve ser 
considerada uma prática educativa eficaz. Existem algumas crianças que não são atendidas apropriadamente na classe regular a tempo inteiro; contudo, estas representam apenas uma pequena percentagem dos alunos com NEE. Nós acreditamos que a classe regular, com os necessários apoios, é o local onde os alunos com NEE devem estar..., tanto os professores titulares de turma, como os alunos com NEE podem necessitar de apoio para desenvolverem práticas inclusivas, mas estes apoios dependem das necessidades do aluno e do professor. A missão de um Departamento de Educação é assegurar a igualdade de oportunidades de acesso, e a promoção de uma educação de qualidade em todo o país. A inclusão é consistente com esta missão, e é uma componente essencial das actuais reformas da escola. A classe regular da área de residência do aluno deve ser a primeira opção de colocação para os alunos com NEE. As experiências e os conhecimentos devem ser partilhados, para implementar um sistema educativo que promova a igualdade e a qualidade de ensino para todos os alunos do nosso país.

Estes resultados são importantes na medida em que permitem um olhar crítico sobre os planos de formação de professores em educação inclusiva que são desenvolvidos nas instituições do ensino superior que participaram no estudo. De ressaltar aqui, o papel das instituições de ensino superior como determinante para atitudes positivas perante a filosofia da inclusão (Correia, Cabral \& Martins, 1997). Muitos profissionais têm de adquirir e/ou aperfeiçoar competências, devido à implementação de um modelo inclusivo. Esta ideia realça um pressuposto essencial para o sucesso da escola inclusiva: a valorização e oferta de oportunidades de desenvolvimento profissional (Hunter, 1999). A filosofia da escola inclusiva, da forma como é compreendida, altera o papel de todos os profissionais da comunidade educativa. Estes têm, agora, uma participação mais activa no processo de ensino-aprendizagem pelo que devem desenvolver, não só competências que lhes permitam responder às necessidades educativas dos alunos, mas também atitudes positivas em relação à inclusão (Lipsky \& Gartner, 1997).

\section{Referências}

Correia, L. M., Cabral, M. C. M., \& Martins, A.P.L. (1997). Pressupostos para o êxito da integração/inclusão. In L.M. Correia (ed.), Alunos com necessidades educativas especiais nas classes regulares (pp.161-168). Porto: Porto editora.

Coutinho, M. \& Repp A. (1999). Inclusion: The integration of students with disabilities. Belmond: Wadsworth.

Decreto-lei 3/2008 de 7 de janeiro. Diário da República: $1^{a}$ Série, ${ }^{\circ} 4$ de 7 de janeiro. Acedido em http://www.dge.mec.pt/legislacao-2.

Hallahan D. \& Kauffman J. (1997). Exceptional Learners: Introduction to special education. Boston: Allyn and Bacon. 
Atitudes de futuros educadores/professores face à Inclusão de alunos com Necessidades Educativas Especiais: Um estudo comparativo entre Portugal e Tailândia

Hunter, D. (1999). Systems change and the transition to inclusive systems. In M. Coutinho \& A. Repp (Eds.), Inclusion: the integration of students with disabilities (pp. 135-151). Belmont, CA: Wadsworth Publishing Campany.

Lieberman, M. (1996). Preserving special education ... for those who need it. In W. Stainback \& S. Stainback (Eds.), Controversial issues confronting special education: Divergent perspectives (pp. 16-27). Boston: Allyn and Bacon.

Lipsky, D. K., \& Gartner, A. (1997). Inclusion and school reform: Transforming America's classrooms. Baltimore: Paul Brookes.

Office of Special Education Administration (2015). Documentation for training. The development of educational master classroom (inclusive school). Bangkok: Author.

Office of Special Education Administration (2014). The result of the development of for model inclusive education in schools ( $2^{\text {nd }}$ ed ). Bangkok: Author.

Pestana, M.H., \& Gageiro, J.N. (2008). Análise de dados para ciências sociais: A complementaridde do spss. Lisboa: Edições Sílabo.

Smith, T., Polloway, E., Patton, J., \& Dowdy, C. (1995). Teaching students with special needs in inclusive settings. Boston: Allyn and Bacon.

UNESCO (1994). The Salamanca statement and framework for action on special needs education. Acesso em setembro 7, 2010 em: unesdoc.unesco.org/images/0009/000984/098427eo.pdf.

Vorapanya, S. \& Dunlap, D. (2014). Inclusive education in Thailand: practices and challenges. International Journal of Inclusive Education, 18(10), 1014-1028, DOI: $10.1080 / 13603116.2012 .693400$ 